Portland State University

PDXScholar

\title{
Assessing Affective Differences between a Virtual General Chemistry Experiment and a Similar Hands- On Experiment
}

Cory Hensen

Portland State University, chensen@pdx.edu

Jack Barbera

Portland State University, jbarbera@pdx.edu

Follow this and additional works at: https://pdxscholar.library.pdx.edu/chem_fac

Part of the Chemistry Commons, and the Online and Distance Education Commons Let us know how access to this document benefits you.

Citation Details

Published as Hensen, C., \& Barbera, J. (2019). Assessing Affective Differences between a Virtual General Chemistry Experiment and a Similar Hands-On Experiment. Journal of Chemical Education, 96(10), 2097-2108.

This Post-Print is brought to you for free and open access. It has been accepted for inclusion in Chemistry Faculty Publications and Presentations by an authorized administrator of PDXScholar. Please contact us if we can make this document more accessible: pdxscholar@pdx.edu. 


\section{Assessing Affective Differences Between A Virtual General Chemistry Experiment and a Similar Hands-On Experiment}

Cory Hensen and Jack Barbera

Department of Chemistry, Portland State University, Portland, Oregon, 97207-0751, United States

ABSTRACT

To date, few general chemistry laboratory studies have included affective measures despite calls for more research on aspects of this domain. This shortage of studies may be partially due to the scarcity of affective measures that have been designed for, or tested in, the college laboratory setting.

To provide measures for use in this environment, several existing affective scales were adapted for this new context. Before data from the scales were utilized to study the environment, evidence was provided for the validity and reliability of the data generated from them. Once sufficient evidence was provided, it was possible to determine affective differences between students completing a Beer's Law experiment in the traditional hands-on laboratory (control group) and a similar experiment in a virtual environment (treatment group). To assess expected differences between environments, scales for anxiety, emotional satisfaction, intellectual accessibility, usefulness of lab, equipment usability, and open-endedness of lab were selected. To account for potential between-student differences, scales for feeling-related initial interest and value-related initial interest were selected. Overall, students who completed the virtual experiment scored significantly lower on the emotional satisfaction, intellectual accessibility, usefulness of lab, and equipment usability scales. However, it was noted that student responses in the virtual environment varied significantly by which teaching assistant (TA) instructed the section. To test for a possible instructor effect, data from the virtual sections were grouped by TA as 'Virtual Group A' and 'Virtual Group B'. Group A contained the TAs who had sections with lower averages on the emotional satisfaction scale as compared to group B. After controlling for instructor, differences between student responses in the 'Hands-On' sections and 'Virtual Group A' sections were no longer significant while significant differences remained between the responses in the 'Hands-On' and 'Virtual Group B' sections. This outcome indicated that the TA instructing the course may have been more influential on students' affective outcomes than the environment in which the experiment was performed. 


\section{GRAPHICAL ABSTRACT}

30
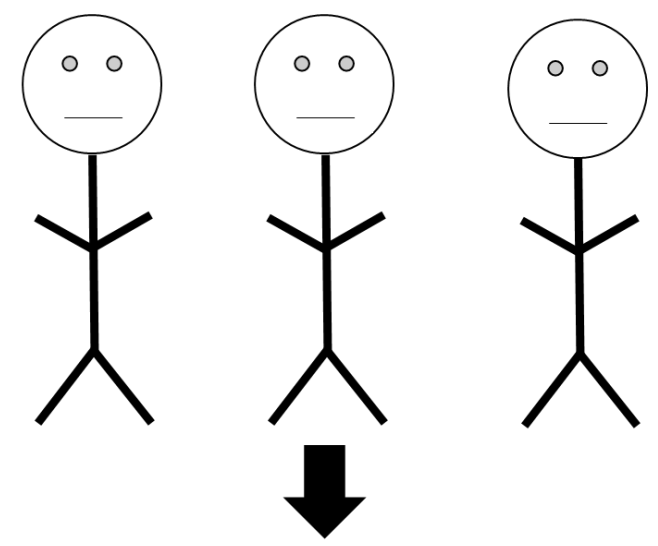

Hands-On Virtual Group A Virtual Group B

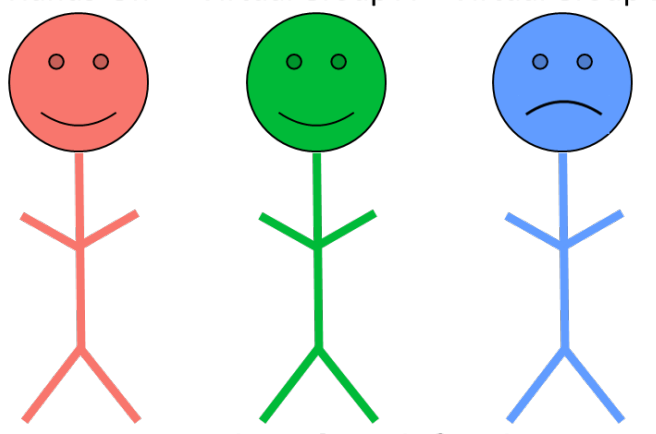

Emotional Satisfaction

\section{KEYWORDS}

General Public, Chemical Education Research, Computer-Based Learning, Distance Learning

\section{Reference Information:}

Cory Hensen and Jack Barbera, "Assessing Affective Differences Between a Virtual General Chemistry Experiment and a Similar Hands-On Experiment," Journal of Chemical Education, 2019, 96, 10, 20972108, DOI:10.1021/acs.jchemed.9b00561. 


\section{INTRODUCTION}

Over the past decade, there has been a steady increase in the number of students electing to take college classes from a distance, which typically involves taking online courses. ${ }^{1}$ While this may provide an acceptable learning experience for courses in many fields, online courses pose a specific challenge to the laboratory component of the chemistry curriculum. Currently, the American Chemical Society (ACS) requires 400 hours of laboratory instruction for a student to earn an ACS certified bachelor's degree. ${ }^{2}$ This requirement highlights the common belief that laboratory courses are essential to an undergraduate chemistry degree. Thus, universities have sought out varying ways to include a chemistry laboratory experience for students who elect to complete courses in a nontraditional environment. One of the most common approaches to address this challenge is to offer a laboratory course that uses at-home kits. ${ }^{3-5}$ These kits allow students to be exposed to laboratory basics, such as glassware and reagents, in a space of their choosing. More recently, institutions have taken advantage of advances in technology to offer alternatives that rely on the use of computers.

The technologic approach can be categorized in two distinct ways. The first category includes experiments that incorporate the use of a remote laboratory environment. Remote laboratories involve a student using a computer interface to control an instrument that is housed at a different institution. ${ }^{6-7}$ For example, a student controls a robotic system to put a sample into an instrument to take a physical measurement and data from the instrument is then reported back to the student. This method allows students to collect real-time data from physical instruments without being physically present for the data collection. The second category includes experiments that simulate the entire process, including data collection. This approach, called a virtual laboratory environment, drastically reduces operating costs as there are no physical laboratory spaces, reagents, or instruments to maintain. There have been a number of different approaches to the virtual laboratory ranging from simple simulations s-9 $^{8}$ to fully-immersive environments ${ }^{10-11}$ and multiple environments in-between. ${ }^{12-15}$

Regardless of which environment is chosen as an alternative to the physical laboratory, it is imperative that potential differences between environments be evaluated to ensure that students have similar outcomes to the students in the traditional hands-on laboratory across the three domains of learning (cognitive, psychomotor, and affective). Outcomes in the cognitive domain include aspects of 
the knowledge acquired in an experiment ${ }^{16}$, outcomes in the psychomotor domain include the skills acquired from the experience ${ }^{17}$, and outcomes in the affective domain include aspects of students' attitudes and emotions regarding an experiment or the learning envrionment ${ }^{18}$. The cognitive domain is frequently measured by administering content-based items such as prelab or postlab quizzes in a laboratory environment or test questions in a lecture environment. The psychomotor domain is frequently measured in the laboratory setting with the use of laboratory practical exams that measure specific skills students are expected that have learned. The affective domain includes a wide range of constructs including motivation, emotion, interest, values, attitudes, and many more. Within each construct, there may be further subconstructs such as self-efficacy within the broader construct of motivation. These constructs can then be targeted for specific interventions and measured to determine whether an intervention has positive or negative impacts. In the college setting, it has previously been reported that motivation, self-esteem, self-perceptions, feelings of confidence, selfconcept of ability, and teacher praise are some of the most important affective constructs to target. ${ }^{19}$ More specifically, for the laboratory the construct of general attitude has been proposed as an important affective construct, as one of the goals of the science laboratory is to increase students' 80 attitude toward science. ${ }^{20}$ Aspects of these three domains need to be measured to determine what, if any, differences exist between learning environments.

\section{Differences Between Traditional and Alternative Environments}

Several studies have been conducted to examine the advantages and disadvantages of incorporating virtual experiments in various curricula ranging from high school chemistry laboratories ${ }^{11,21}$ to upper-division college laboratories ${ }^{13-14}$. These studies generally fall into two categories. The first category includes comparative studies that examine differences between a virtual and a traditional hands-on experiment using treatment and control groups. The second category includes studies that describe the virtual environment used and the potential advantages and disadvantages they have without the use of a comparative group.

At the general chemistry level, Hawkins and Phelps conducted a comparative study with 84 students completing a virtual electrochemistry experiment and 85 students completing the equivalent traditional hands-on experiment. ${ }^{15}$ The students completed a pretest and a posttest content knowledge 
quiz to determine if there were any cognitive domain differences between the groups. No statistical difference between the two groups was detected. As there were remaining questions if virtual experiments could provide the same psychomotor outcomes as a traditional hands-on laboratory environment, the researchers measured both groups' ability to complete a hands-on practical regardless of which environment they completed the experiment in and again no statistical difference was detected. While the researchers concluded that no differences were detected between environments in the cognitive and psychomotor domains, they did not measure any aspects of the affective domain.

A comparative study that focused on potential differences in the affective domain was conducted by Pyatt and Sims at the high school level. ${ }^{21}$ In their study, students were assessed using a newly created affective instrument, the Virtual and Physical Experimentation Questionnaire (VPEQ), that measured students' attitude towards various aspects of the two environments. This instrument measured aspects of usefulness of computers, anxiety towards computers, equipment usability, openendedness of lab, and usefulness of lab. Within-person differences were controlled for by using a $2 \times 2$ Latin square (crossover) study design in which the 184 students completed both a virtual experiment and a traditional hands-on experiment. ${ }^{22}$ Results indicated a higher average for the virtual experiment for the constructs of equipment usability and open-endedness of lab but no detectable difference between environments for the construct of usefulness of lab. The significance of these differences was not tested. In addition to these affective constructs, cognitive domain differences were measured by scoring laboratory reports. The first experiment was scored using a binary scale whereas the second was scored on a four-point scale. No significant difference was detected between groups in the first experiment but a significant difference was detected in the second experiment, with the scores of the students who completed the traditional hands-on experiment being significantly lower than the scores of the students who completed the virtual experiment. The scoring system for the cognitive assessments changed between experiments to allow for more resolution and thus could explain why significance was found for the second experiment but not the first. Future work should be done to elaborate on the affective and cognitive differences seen in this comparative study and how they compare to the collegiate level. 
Grove and colleagues measured differences across all three domains of learning for a college hybrid curriculum that incorporated LearnSmart Labs by McGraw-Hill Education. ${ }^{23}$ Rather than measure differences for a specific experiment, the differences measured were for the entire hybrid curriculum as a whole. In total, 195 students completed the hybrid curriculum across the 2015 calendar year. In this curriculum, students alternated between a virtual experiment and a traditional hands-on experiment. There were no statistically significant differences found when measuring cognitive outcomes using the ACS General Chemistry Laboratory Assessment or psychomotor outcomes using a hands-on laboratory practical. However, the hybrid students had a significantly lower mean scale score on the affective portion of the Meaningful Learning in the Laboratory Instrument (MLLI), which has 8 items that measure a general affective state. Upon further examination of the items, it was revealed that students in the hybrid curriculum had lower affective aspects with the exception of worrying about completing the lab on time when compared to the handson students, however, it was not possible to determine what differences were specific to the virtual environment as the hybrid curriculum included both types of experiments and data was collected only at the beginning and end of the curriculum.

Irby and colleagues focused more narrowly within a hybrid curriculum to better understand if students who completed an electrical conductivity experiment in a virtual environment engaged with the chemistry triplet ${ }^{24}$, which models the different levels of understanding in chemistry: submicroscopic, macroscopic, and symbolic, to a different degree than students who completed a similar hands-on experiment. ${ }^{25}$ Their study utilized a pretest-posttest alternative treatment with a control group study design ${ }^{26}$ where there was a control section that did not use the hybrid curriculum and two treatment sections that did. The two treatment sections were staggered so that in any given week, one section was completing a hands-on experiment while the other section was completing a virtual experiment on a different topic. This allowed for the institution to offer three laboratory sections while only having two laboratory rooms available. However, this meant that the control section and the two treatment sections had a different order of experiments over the course of the term. For example, the "leading" hybrid section completed the conductivity experiment in week seven whereas the "trailing" hybrid section and the hands-on students completed the experiment in week six. After 
comparing the sections, no statistically significant differences were found on the cognitive outcomes, as measured by pre- and post-assessments, nor students' use of the chemistry triplet. However, the authors note that this could be a function of the small sample size as the students who completed the experiment in the virtual environment appeared to connect between the triplet levels more often despite the difference not being statistically significant.

Winkelmann and colleagues used the virtual platform Second Life (SL) to measure differences across the three domains of learning for two specific experiments rather than a hybrid curriculum. ${ }^{10}$ In this study, 55 students completed both a gas law experiment and a titration experiment in the SL platform while 67 students completed both experiments in a traditional hands-on (control) environment. Both the control and the SL group showed cognitive gains on the post-quiz as compared to the pre-quiz, however, the SL group had significantly higher gains in both experiments. Within the psychomotor domain, students in both groups performed equally well on a follow-up hands-on laboratory practical. To measure differences within the affective domain, students were asked general questions authored by the researchers about their experience in the respective learning environment. These general questions were elaborated on in written responses and focus groups. Students reported that the SL experiments took less time to complete, they felt that they learned more in the traditional hands-on experiment, and had higher perceived grades in the SL experiment as compared with previous hands-on experiments. Future research can expand on these findings by using affective instruments with measured psychometric properties rather than general self-authored questions.

The second type of commonly conducted study pertaining to alternative labs does not contain a traditional hands-on laboratory control group. Instead, in descriptive studies, the advantages and disadvantages of a specific virtual platform are investigated. Winkelmann and colleagues conducted a study on SL at the high-school level before conducting the comparative study at the college level. ${ }^{11}$ In this study, seven high school students completed a SL experiment as part of a summer class. The students were evaluated on aspects of their attitude using a modified version of the Inquiry Laboratory Attitudes Survey ${ }^{27}$. However, the scale was developed for inquiry-labs and had not been psychometrically evaluated for the new context. The students were also evaluated on their cognitive outcomes by assessing their laboratory report. The students were able to successfully complete the 
experiment, as indicated by their laboratory report score, and reported that they felt the SL experiment was shorter than their other experiments in the term. In addition to this study, descriptions of how SL can be used more broadly in chemistry as a discipline has been the subject of multiple articles. ${ }^{28-29}$

Woodfield and colleagues created a suite of virtual experiments including one as part of an inorganic laboratory curriculum ${ }^{14}$ and one as part of an organic laboratory curriculum ${ }^{13}$. These studies are descriptive in nature and thus they did not have a control group. In their inorganic study, they found that students were able to use the virtual environment to complete experiments that would be challenging to complete in a traditional hands-on laboratory setting. For example, the students were given 26 cations and 11 reagents that they could combine, which would have required significant prep time for the traditional hands-on laboratory. Many of the students reported qualitatively that the virtual experiment helped them learn the content. Similarly, in their organic study, they found that the students who had a positive experience with the virtual experiment were more likely to have a higher course grade. Unlike the Hawkins and Phelps study, Woodfield and colleagues focused more on affective differences. They found that students in both the inorganic and organic study preferred the virtual experiment for the adaptability of the environment to perform experiments that are not as feasible to do in traditional hands-on laboratories. However, they used general Likert-type items to ask affective questions that were not rooted in any specific construct and also they did not measure any psychomotor outcomes.

Overall, the comparative and descriptive studies on virtual experiments in the chemistry curricula point to either no difference ${ }^{11,15}$ or a slight potential benefit ${ }^{10,13-14,21}$ in the cognitive domain when students complete the experiment virtually. This is in line with studies measuring the cognitive domain when the alternative environment is an at-home kit $^{3,30}$ or a remote environment ${ }^{31-34}$. In addition to the cognitive domain, there was no difference in the students' ability to perform the laboratory skill covered in the experiment for the studies that included a psychomotor measure. ${ }^{10,15}$ However, of the comparative and descriptive studies, only one study used an affective measure that has been psychometrically tested. ${ }^{21}$ The remaining studies either did not measure the affective domain, or used items that had unknown psychometric properties to measure the affective domain. This is a common challenge across all laboratory studies and not solely on studies involving 
alternative environments, as there have been few affective measures developed or adapted for chemistry laboratories.

\section{Affective Domain Measures for the Laboratory}

In response to a historically heavy focus on cognitive outcomes in research studies, the National Research Council has called for studies in discipline-based education research (DBER) to include the evaluation of outcomes within the affective domain. ${ }^{35}$ Despite this call, a majority of chemistry laboratories studies either provide limited scope to the affective domain or do not include it at all. A primary reason for this has been the lack of affective measures designed for and tested specifically in the laboratory. A recent instrument, the MLLI ${ }^{36}$, was designed to address this issue and it has allowed researchers to study how aspects of the affective domain in the laboratory change over time $^{37}$ and based on an intervention ${ }^{38-39}$. Additionally, it has been used to categorize student profiles ${ }^{40}$. Another example of an affective instrument developed specifically for the laboratory is the chemistry laboratory anxiety instrument (CLAI) ${ }^{41}$.

While not developed specifically for the laboratory, instruments to measure various aspects of the affective domain of chemistry students include the Metacognitive Activities Inventory (MCAI) ${ }^{42}$, the Chemistry Expectations Survey $(\mathrm{CHEMX})^{43}$, the Chemistry Self-Concept Inventory $(\mathrm{CSCI})^{44}$, the Attitude toward the Subject of Chemistry (ASCI) ${ }^{45}$ and the revised version (ASCIv2) ${ }^{46}$, the Colorado Learning Attitudes about Science Survey (CLASS-Chem)47, and the Academic Motivation Scale (AMSChem) ${ }^{48}$. These instruments serve as potential measures for the affective domain in the laboratory setting. However, for any of these instruments to be used in studies of the laboratory environment their functioning in this new context would need to undergo psychometric testing to ensure that there was sufficient evidence of data validity and reliability.

\section{Psychometric Testing}

Whenever an instrument is distributed within a different setting than originally developed for, evidence for the validity and reliability of data from the instrument in the new context needs to be provided. ${ }^{49-51}$ For example, it is possible that questions asked in a classroom setting do not function in the same way in a laboratory setting. Thus, the internal structure of the instrument could be different and pose a threat to the validity. Another issue that could arise from adapting an existing instrument 
to a new context is that students no longer interpret the questions as they were initially intended. For example, an item asking if the student "feels comfortable" may be interpreted in multiple ways. One way students may interpret the item is if they feel comfortable with big-picture concepts but alternatively, it may be interpreted is if they feel physically comfortable in the laboratory setting itself. Differences like this pose a threat to the response process aspect of validity. ${ }^{52}$ Additionally, to accurately compare treatment and control groups with the same instrument, invariance testing needs to take place to show that both groups have the same relationship to the variables being measured. ${ }^{53}$ If evidence is provided that items are functioning in both contexts, it is possible to use the items to measure meaningful differences between groups.

\section{Research Questions}

Previous work on the differences between traditional hands-on and alternative laboratory environments has found very little or no difference on measures in the cognitive domain, however, there have been fewer studies on the differences in the affective domain. This study aims to address this gap by investigating differences between a virtual environment and a traditional hands-on environment within the affective domain of learning. Before differences can be tested, evidence for the validity and reliability of the data generated from the scales used needs to be provided. As such, this research is guided by the following three questions:

1. To what degree can previously developed scales be adapted for use in the laboratory environment?

2. What evidence of validity and reliability supports data collected with the adapted scales?

3. How do various aspects of the affective domain compare when students complete a general chemistry experiment virtually as opposed to a traditional hands-on experiment?

\section{Methodology}

A post-test-only alternative treatment control group research design was chosen to investigate the effect of virtual experiments on affective outcomes. ${ }^{54}$ To address Research Question 1, several affective scales were selected and modified for use in the laboratory setting. Cognitive interviews were used to evaluate the validity of the modified scales. The scales were distributed within the interview 
format to determine how students responded and to assess any issues with the response process for the selected items. To address Research Question 2, psychometric analysis was performed to address the internal structure of the individual scales, the scales relation to each other, and the internal consistency of the scales. To address Research Question 3, comparative statistics were used to determine what, if any, affective differences existed between environments. As this project has multiple facets, the research questions will be used to organize the methodology and results sections.

\section{Human Subject Research}

All parts of this research were approved by the institutional review board at the author's home institution, Portland State University. Participants in the laboratory courses had the option to provide informed consent and only those participants who consented are represented in the data.

\section{Research Question 1: Selection of Scales}

Anderson summarized that there are seven central student affective characteristics: values, academic self-esteem, anxiety, interests, locus of control, attitudes, and preferences. ${ }^{55}$ Anxiety, attitudes, and interests were chosen for inclusion in this study. The selection was limited to three to avoid survey fatigue, thereby reducing the chance of students reporting less thoughtful answers. The Attitude toward the Subject of Chemistry Inventory (ASCI) scales for the cognitive aspect of attitude (intellectual accessibility) and the affective aspect of attitude (emotional satisfaction) were selected based on one of the general goals of the chemistry laboratory; to increase students' attitude toward science. ${ }^{20}$ The original ASCI scales were chosen over the modified version of the scales (ASCIv2) because the scales were being adapted for a new context. Thus, all original items were tested as it was unclear if the modifications made would be the same modifications needed for a different context. Additionally, there may be differences in students' anxiety as those completing an experiment within technology-based alternative environments, such as a virtual environment, do not need to consider the safety hazards of chemicals nor do they have to wear proper personal protective equipment (PPE). Therefore, an anxiety scale based on the Chemistry Laboratory Anxiety Instrument (CLAI) and the ASCI anxiety scale was created. There may also be specific environment differences, such as ease of equipment use, and thus items from the Virtual and Physical Experimentation Questionnaire (VPEQ) were selected. Beyond these differences, there may be differences in students' incoming interest 
towards chemistry. To control for any incoming differences, an interest scale previously adapted for chemistry $^{56}$ was selected. The modified version of each scale used in this study is provided in the Supporting Information.

\section{Research Question 1: Modifying and Adapting Selected Scales}

\section{Emotional Satisfaction and Intellectual Accessibility}

The ASCI and the modified version (ASCIv2) have been widely used to measure students' attitude changes across the implementation of an intervention. ${ }^{57-59}$ Although the ASCI was originally administered in the laboratory ${ }^{45}$, the items were operationalized to chemistry as a whole. Therefore, the frame of reference of these scales was altered by changing from the original frame of reference of "Chemistry is..." to "This experiment was...". The emotional satisfaction and intellectual accessibility scales are comprised of semantic differential questions. A semantic differential question contains a spectrum between two polar opposite words such as safe and unsafe. ${ }^{60}$ The administration of the scales was done electronically and as a result, it was possible to change the original seven-point semantic differential scale to a sliding scale from 0 to 100 . This change allowed the students to select anywhere along the spectrum. No additional changes were made to the scales.

\section{Anxiety}

Students' anxiety levels may differ between laboratory environments and have been shown to be related to student attitude. ${ }^{45}$ While the original ASCI did have semantic differential items on anxiety, there was little reasoning given for why some of the word pairs were chosen. For example, it was unclear how the 'disgusting-attractive' item pair informed aspects of anxiety. Therefore, after careful review of the original ASCI anxiety items, only the 'relaxed-tense' pair was selected for use. In addition to this item, the stems from the twenty items on the Chemistry Laboratory Anxiety

Instrument (CLAI) were used to create additional anxiety semantic differential item pairings. For example, multiple CLAI items measured students' nervousness while performing a range of tasks and therefore 'nervous' was chosen as one of the words for the semantic differential. The opposite word for each word pair was decided by the researchers and were later tested for evidence of validity. For the case of nervous, calm was chosen as the opposite word. In total, there were four word pairs selected 
based on the CLAI stems that, with the original ASCI item, gave a total of five word pairs: nervouscalm, safe-unsafe, anxious-unconcerned, apprehensive-at ease, and relaxed-tense.

\section{Usefulness of Lab, Equipment Usability, and Open-endedness of Lab}

The VPEQ was designed to measure specific differences between the virtual environment and the traditional hands-on environment when used in a crossover research design. ${ }^{21}$ The 39 original items were analyzed to determine which could be modified to fit the current research design in which students complete an experiment in either the treatment or the control environment. For example, item 11 stated "the regular lab experiments worked better than the computer experiments" and item 29 stated "computer simulations work better than regular experiments". These items were combined to ask students if the experiment worked well. After analyzing the original items, ten items were selected that could be generalized or modified for use in the current research design. These ten items were given on a five-point (strongly agree-strongly disagree) Likert-type scale.

\section{Interest Scale}

In addition to expected differences across environments, there may be additional differences between students that could relate to their laboratory experience and outcomes. Previous research found a link between students' incoming interest levels and course performance. ${ }^{61}$ Therefore, the two components of initial interest, feeling-related interest and value-related interest, were measured to account for potential differences in incoming ability. ${ }^{62}$ As these scales were adapted to measure students' incoming general interest in chemistry, no modifications were required. However, they had not been applied to or evaluated within the laboratory environment prior to this study.

\section{Research Question 1: Scale Testing}

\section{Response Process Validity}

Students were recruited for a response process interview from the general chemistry laboratory sections during the Winter 2017 term. Classroom announcements were made at the beginning of a laboratory period and students were provided a link to sign up for interview slots. Participants were compensated (\$20 gift card) for participating in the interview. During the interview, participants completed the items from the anxiety, emotional satisfaction, intellectual accessibility, usefulness of lab, equipment usability, open-endedness of lab, initial interest-feeling, and initial interest-value 
scales one item at a time. For each item, they were asked to provide their reasoning for selecting a particular response to determine if there was evidence for response process validity. This type of validity is an evaluation of the respondents understanding of an item to ensure its alignment with the authors intended meaning. ${ }^{52,63}$ If the rationale students provided was not aligned with the researcher's intended meaning, the item was flagged for modification or removal. If students gave a rationale that was aligned with the intended meaning, there was validity evidence that the item was being interpreted as intended and could be used in future implementations of the scale in the given context.

\section{Research Questions 2 and 3: Implementation of Experiments}

\section{Population}

All sections of the general chemistry laboratory at Portland State University were assigned to complete the selected experiment in either the virtual environment (treatment group) or the traditional hands-on environment (control group). This is an approximately random selection as students enroll in the section that best fits their schedule. Students were not made aware ahead of time which sections would complete the experiment in a virtual environment. A total of 28 sections of the general chemistry laboratory taught by 14 graduate teaching assistants (TAs) were offered in the Fall 2018 term with a total enrollment of 634 students. Sixteen of these sections completed the virtual experiment and twelve sections completed the traditional hands-on experiment. For logistical reasons, the sections were unable to be balanced at fourteen sections for each environment. While all students completed the experiment in their section's assigned environment, only responses from students who consented to participate in the study were analyzed.

\section{Experiment Selection and Design}

The concept of Beer's Law is commonly covered in an experiment during the first term of a general chemistry laboratory sequence and as such was selected for this research study. In this institution's hands-on experiment, students use a known concentration of Allura Red to make a calibration curve and calculate the concentration of Allura Red in red Gatorade. The matching virtual experiment was chosen as the 'Spectrophotometry: Calibration Curves' experiment within LearnSmart Labs by McGraw-Hill Education. In this virtual experiment, students are randomly given either a red, 
yellow, or blue dye. They are given five prefilled test tubes with known concentration of the selected dye to create the calibration curve and a test tube with unknown concentration. Additionally, since the virtual students did not have to create their own solutions from a stock solution, they were also tasked with first completing the 'Dilute Solutions' experiment in the LearnSmart environment. This experiment had them dilute a stock solution to two different concentrations, which allowed them to still gain practice with the concept of diluting a stock solution.

\section{Data Collection}

Students completed either the traditional hands-on or virtual experiment in the laboratory room with their TA and laboratory partner. Once students completed the experiment, the TA prompted them to use the laboratory computers to answer the scale items administered through the Qualtrics program. Included among the scale items was a 'check item'. A check item is a question that asks students to select a specific response option to ensure that students are carefully reading and responding to the items. For this study, the check item read "Please select strongly agree for this question". Therefore, it is assumed any student who did not select strongly agree for the question was not carefully reading the items and thus their data was not used for analysis.

\section{Research Question 2: Analysis}

After collecting the affective item responses, the structure of the scales was examined to provide evidence of the internal structural validity of each scale. To do this, confirmatory factor analysis (CFA) was used to evaluate a priori models of each scale. The analyses were conducted using version $0.6-3$ of the $\mathrm{R}$ package lavaan ${ }^{64}$. To account for any non-normality in the data, the maximum likelihood with Satorra-Bentler corrections (MLM) estimator was used for all CFA models. Additionally, previous research provided links between the feeling and value aspects of interest 56 and between the constructs of anxiety, emotional satisfaction, and intellectual accessibility ${ }^{65}$. Therefore, a two factor and a three-factor model, respectively, were tested to confirm those relations. All scales were reviewed for potential modifications if individual factor loadings were below a cutoff value of 0.4 or if the fit indices were out of range (i.e., CFI below 0.95, SRMR above 0.08, and/or RMSEA above 0.06) as recommend by $\mathrm{Hu}$ and Bentler. ${ }^{66}$ Additionally, the internal consistency of each scale was tested and modifications were made if any scales had an omega value below the generally accepted cutoff value of 
0.70. McDonald's omega is similar to the commonly reported alpha but is more appropriate for congeneric models, which is a model where factor loadings and error terms are not constrained to be equal. ${ }^{67}$ Therefore, single-factor congeneric CFA models were tested for each scale.

\section{Research Question 3: Analysis}

Once all scale data was deemed to have acceptable model fit, invariance testing took place to examine if both the treatment and control groups responded to the items in a similar fashion. To test into a single data set. If the global model fit is still within the acceptable range when the model is tested by group (with equal loadings and intercepts) or if the CFI changes by less than or equal to 0.01, then measurement invariance is determined and the two groups can be compared on the affective items. ${ }^{68} \mathrm{~A}$ relatively small change in the CFI indicates that specifying the model to have equal loadings and intercepts did not change the model in a meaningful way. This indicates that the two groups were responding in a similar fashion. If the model fit changed drastically then further investigation of the response differences would be warranted. Once invariance was determined, a multivariate analysis of variance (MANOVA) was conducted using version 24 of SPSS to evaluate group means on multiple affective scales to determine if there are any statistical differences in the measured affective domain aspects between the virtual and traditional hands-on environment.

\section{RESULTS}

\section{Research Question 1: Response Process Validity}

Ten students participated in an interview. Each student completed the items from scales one item at a time and then gave their reasoning for their response selection. For example, on the intellectual accessibility scale, a student selected that the experiment was closer to the 'confusing' side of the word pair 'confusing-clear' because "I think the procedure was a little unclear". This response aligned with the intended interpretation of the word pair and thus provided evidence for response process validity. For all but one item, students gave reasoning for their selected answer that correctly aligned with the intended meaning of the item. This increased the confidence that the newly created anxiety scale was functioning as intended. All ten students struggled to correctly interpret the item, "There is opportunity for me to pursue my own experimental interests" from the VPEQ usefulness of 
lab scale. All students interviewed were confused about what the term "experimental interests" meant. Therefore, this item was discarded and all other items were retained.

\section{Research Questions 2 and 3: Population}

There were 634 students enrolled in the first term general chemistry laboratory in the Fall 2018 term. Of those students, 448 students consented to have their data analyzed. There were 52 students who incorrectly responded to the check item "Please select strongly agree for this question" and thus were removed from the data set leaving 396 students in the final cleaned data set of which 178 of the students completed the traditional hands-on experiment and 218 completed the virtual experiment.

Research Question 2: Reliability and Validity Evidence of Data Provided By Scales

\section{Individual Model Testing and Modifications}

Before the difference in means between laboratory environments were analyzed, the scales were tested individually as single-factor, congeneric, CFA models to ensure they functioned as intended. This took place for each scale with four or more indicator items before analyzing the relations between individual scales. The equipment usability and open-endedness of lab scales each consisted of two items and the initial interest-value scale consisted of three items. Thus, it was not possible to test the model fit for these scales as they would not be over-identified models. ${ }^{69}$

Single-factor model results for the anxiety scale indicated that each fit statistic was outside the chosen cutoff criteria (Table 1). Additionally, the CFI for the intellectual accessibility scale was outside of the chosen cutoff. All other scales had CFI and SRMR values that were within the acceptable cutoff range and most scales had RMSEA values outside of the cutoff range, as shown in Table 1. However, when the degrees of freedom in a model are low (e.g. less than 50), the RMSEA is biased and should be interpreted with caution. ${ }^{70}$ The degrees of freedom are low for these models and as such the RMSEA was not used as a primary indicator of fit. The lack of model fit for the anxiety and intellectual accessibility scales required further investigation before analysis.

Along with model fit, the internal consistency of each scale with four or more items was tested. Cronbach's alpha is commonly used to measure this reliability, however, as the single-factor models 
were tested as congeneric, McDonald's omega was more appropriate. ${ }^{67}$ All scales had an acceptable internal consistency as shown by the omega value in Table 1 .

As the anxiety scale did not have acceptable fit, the loadings were examined and it was noted that the word pair 'safe-unsafe' loading was 0.165 , which was significantly lower than the other items and below the chosen cutoff value of 0.4. Therefore, this item was removed and upon retesting the single-factor model, the anxiety scale had acceptable fit indices, as noted as 'modified anxiety' in Table 1 , and had satisfactory internal consistency. The loadings of the intellectual accessibility scale did not have any values below the chosen cutoff value, therefore, the modification indices of this scale were investigated to determine if there were feasible relations between variables that would improve model fit. A high modification index between the error terms of the 'hard-easy' and 'challengingunchallenging' word pairs was detected. Cohen's $w$ was calculated to determine the effect of correlating these terms, it was determined that the modification would result in a large effect of $0.46 .{ }^{71}$ Given the large effect and the word pair similarities, it is possible that they did not have independence of errors and thus the error terms for these items were correlated. This modified model showed acceptable model fit with good internal consistency, noted as 'modified intellectual accessibility' in Table 1.

Table 1: Fit indices and internal consistency values for single-factor models. Indices in italics are outside of the recommended range. Omega values are only shown for congeneric models deemed to have acceptable fit.

\begin{tabular}{r|ccccc} 
& CFI & SRMR & RMSEA & df & Omega \\
\hline Emotional Satisfaction & 0.95 & 0.04 & 0.26 & 2 & 0.88 \\
Intellectual Accessibility & 0.91 & 0.05 & 0.22 & 5 & --- \\
Anxiety & 0.85 & 0.09 & 0.21 & 5 & --- \\
Modified Intellectual Accessibility & 0.99 & 0.02 & 0.10 & 4 & 0.85 \\
Usefulness of Lab & 1.00 & 0.01 & 0.05 & 2 & 0.85 \\
Initial Interest-Feeling & 0.98 & 0.02 & 0.14 & 2 & 0.88
\end{tabular}

Two-factor and Three-factor Model Testing

The ASCI scales were published with correlations between anxiety, intellectual accessibility, and emotional satisfaction. Therefore, a three-factor model was tested to determine if the newly created anxiety scale correlated to the existing scales in a similar fashion. The four-item anxiety scale, the emotional satisfaction, and the intellectual accessibility with the correlated item error term were 
tested as a three-factor CFA model, as seen in Figure 1. The three-factor model produced acceptable fit indices (CFI: 0.95, RMSEA: 0.08, SRMR: 0.04) allowing correlation comparisons to be made to the previously reported values.

The three-factor model had a strong positive correlation between the intellectual accessibility and emotional satisfaction factors (0.91). Both intellectual accessibility and emotional satisfaction correlated negatively with anxiety (-0.65 and -0.66 respectively), as expected. ${ }^{45}$ Bauer reported the correlation between anxiety and emotional satisfaction as -0.72 , between anxiety and intellectual accessibility as -0.58 , and between emotional satisfaction and intellectual accessibility as 0.62 .45 While the correlation to anxiety is similar, Bauer used different word pairs for the anxiety scale and did not have a correlated error term for intellectual accessibility. Similarly, Xu and Lewis did not have the correlated error term, had one less item for intellectual accessibility and did not include an anxiety scale in their ASCIv2. Even with the differences, they reported a similar correlation of 0.80 between their version of emotional satisfaction and intellectual accessibility. ${ }^{72}$ These correlations were similar to the previously reported correlations with the exception of the correlation between emotional

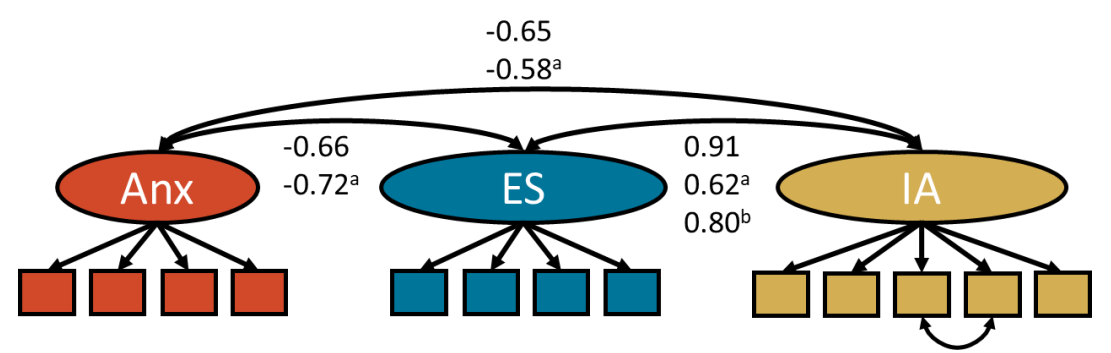

satisfaction and intellectual accessibility, which was higher than previously reported. This could indicate that the affective and cognitive aspects of attitude may not be as distinct in the laboratory environment using these scales or that the addition of the original fifth item and the correlated error term strengthened the relation between the scales.

Figure 1: Three-factor model showing correlations between ASCI scales including Anxiety (Anx), Emotional Satisfaction (ES), and Intellectual Accessibility (IA). Correlation coefficients from original ASCI (a) ${ }^{45}$ and ASCIv2 (b) ${ }^{46}$ shown for comparison.

The interest scale had been previously reported in the literature as a two-factor model. 56 Thus, the 'feeling' and 'value' components were tested as a two-factor model and produced an acceptable fit (CFI: 0.98, RMSEA: 0.07, SRMR: 0.03). The correlation between the 'feeling' and 'value' factors was 0.77 , which was similar to the reported value of 0.69 as noted in Figure 2. 


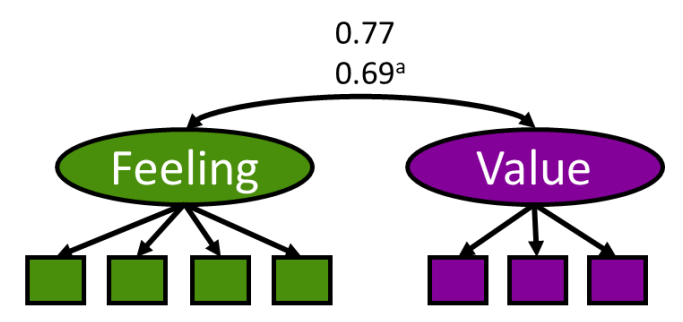

Figure 2: Two-factor model and correlations between initial interest scales. Correlation coefficient from original Ferrell and Barbera data (a) ${ }^{56}$ shown for comparison.

After testing the models, it was determined that the three-factor model of the anxiety, emotional satisfaction, intellectual accessibility scales and the two-factor model of the initial interestfeeling and initial interest-value scales had acceptable fit in this context and produced similar correlations to their prior setting and format. These results added to the confidence that the scales were functioning as intended, including the initial interest-value scale that could not be evaluated as a single-factor model. However, before the individual scales can be used to compare the two environments, measurement invariance had to be shown to ensure that both groups were responding to the scales in a similar manner.

\section{Invariance Testing}

Each single-factor model was retested by group to measure the change in the global fit indices with equal intercepts and loadings. Under these conditions, the CFI for all models only changed slightly except for the one-factor intellectual accessibility model, as shown in Table 2 . This result indicates that both the virtual and the hands-on students were interpreting the scale items similarly and a comparison between group means could be made for the individual scales. The intellectual accessibility scale had acceptable fit indices, despite the relatively large change in CFI, when tested as a grouped model (CFI: 0.95, SRMR: 0.07, RMSEA: 0.13) and as such, it was also deemed acceptable for inclusion in the group mean analysis.

Table 2: Difference in fit indices for models by group.

\begin{tabular}{|c|c|c|c|c|}
\hline & $\triangle \boldsymbol{C F I}$ & $\Delta \mathbf{S R} M \boldsymbol{R}$ & ARMSEA & $d f$ \\
\hline Emotional Satisfaction & -0.01 & 0.01 & -0.09 & 10 \\
\hline Intellectual Accessibility & -0.04 & 0.05 & 0.03 & 16 \\
\hline Anxiety & -0.01 & -0.03 & -0.03 & 10 \\
\hline Usefulness of $L a b$ & -0.01 & 0.04 & 0.01 & 10 \\
\hline Initial Interest-Feeling & 0.01 & 0.01 & -0.07 & 10 \\
\hline
\end{tabular}


With evidence of scale invariance established, group comparisons were made. The raw average scale scores for the affective scales are presented in Table 3. The anxiety, emotional satisfaction, and intellectual accessibility were collected on a 0 to 100 sliding scale. The remaining scales were on a 5 point Likert-type scale.

Table 3: Raw averages for the affective scales

\begin{tabular}{r|cccccccc} 
& Anx & ES & IA & II-F & II-V & U & EU & OE \\
\hline Hands-On & 32.71 & 72.28 & 66.10 & 3.76 & 4.32 & 3.78 & 4.21 & 3.54 \\
Virtual & 35.68 & 60.33 & 57.80 & 3.69 & 4.23 & 3.47 & 3.75 & 3.54 \\
Anx: anxiety, ES: emotional satisfaction, IA: intellectual accessibility, II-F: initial interest-feeling, &
\end{tabular}

A MANOVA was performed to compare groups using the average scores of the individual scales after checking the assumptions for a MANOVA. The first four assumptions are a function of the study design. All scales chosen were either Likert-type or continuous scales and as such were treated as interval data. It is appropriate to treat composite scores from Likert-type scales as interval data whereas individual item scores should be treated as ordinal data as the differences between responses options are unequal. ${ }^{73}$ Students completed the experiment in only one environment and thus there were independent groups. As students can randomly enroll in whichever section fit their schedule best, there were also independent observations within each group. Additionally, a chi-square test found no statistically significant difference for gender, race, or age between students in the two environments. There were 396 students in the data set, which is a sufficient sample size to conduct the MANOVA.

The last five assumptions are not a function of the study design and need to be checked statistically. Multivariate outliers were tested for using Mahalanobis distance. ${ }^{74}$ This is a measure of the distance between two points in multivariate space and is used to find rare combinations of variables. For example, students who responded they were simultaneously anxious and comfortable. There were six multivariate outliers found that were above the chi-square value of 26.13 and all six completed the virtual experiment. These six data points were removed before further analysis took place. Multivariate normality was not directly assessed, however, the normality of each scale was evaluated using the skewness and kurtosis values. The skewness for initial interest-value and 
equipment usability were both below the generally accepted cutoff for normal data of negative one. ${ }^{75}$ All other values were within the range of negative one to positive one. A MANOVA is robust to skewness $^{76}$ and therefore it is still possible to analyze the data with the skewness in the two scales. To test if there was a linear relationship between groups for each scale, scatterplots by group for each scale were analyzed and there was a linear trend in the scatterplot for all scales. Homoscedasticity is measured to ensure students in both environments had similar variances on the affective scales. Homoscedasticity was assessed through Levene's test and it was found that the scales intellectual accessibility, emotional satisfaction, usefulness of lab, equipment usability, and open-endedness of lab all had a significant result indicating that the variances were different between groups of students. Similarly to skewness, a MANOVA is robust to homoscedasticity violations and can still be conducted. Lastly, the variance inflation factor (VIF) was tested and all scales had a value greater than one and less than ten, which means that there was no multicollinearity. Multicollinearity is measured to ensure that no two variables are so highly correlated that they are essentially measuring the same construct.

The results of the MANOVA indicated that there were significantly lower averages on emotional satisfaction, intellectual accessibility, usefulness of lab, and equipment usability for the virtual students. The emotional satisfaction and equipment usability scale score differences had a medium effect size, as measured by partial eta squared ${ }^{77}$, while the differences in intellectual accessibility and usefulness of lab scale scores had small effect sizes. The significant differences are represented in bold in Table 4 and the full MANOVA results can be found in the Supporting Information. No statistical difference between groups was detected for initial interest-feeling, initial interest-value, anxiety, or open-endedness of lab and as such, these scales were not included in further analyses.

Table 4: Significance and effect size of the group mean differences

\begin{tabular}{r|cl} 
& p-value & \multicolumn{1}{c}{ Effect Size } \\
\hline Anxiety & 0.237 & 0.004 (small) \\
Emotional Satisfaction & $<\mathbf{0 . 0 0 1}$ & 0.049 (medium) \\
Intellectual Accessibility & $\mathbf{0 . 0 0 1}$ & 0.027 (small) \\
Initial Interest-Feeling & 0.466 & 0.001 (small) \\
Initial Interest-Value & 0.238 & 0.004 (small) \\
Usefulness of Lab & $\mathbf{0 . 0 0 1}$ & 0.028 (small)
\end{tabular}




\section{Equipment Usability $\mid<\mathbf{0 . 0 0 1} 0.056$ (medium) \\ \begin{tabular}{l|ll} 
Open-endedness of Lab & $0.971 \quad 0.000$ (small)
\end{tabular}}

While the initial MANOVA revealed significant differences between environments, there were 14 graduate TAs in charge of teaching the laboratory and the differences detected could be the result of an instructor-effect and not necessarily reflective of the environment itself. To investigate for this possibility, the students' scale scores were plotted by which TA taught their section, an example is seen in Figure 3. While it would be possible to conduct a MANOVA with posthoc tests to determine if the averages by TA were statistically different from each other, the sample size by TA in this study do not provide sufficient power to warrant such a test. Given this limitation, the data was examined visually. Upon inspection, it was noted that students who completed the virtual experiment with TAs numbered 11-14 (Figure 3) had a lower average for emotional satisfaction than those who completed the virtual experiment with the other TAs (7-10). Therefore, it was possible that the differences in TAs were influencing the significant differences found in the initial MANOVA. To test this, the data from the sections taught by TAs 1-6 were grouped together (Hands-On), by TAs 7-10 were grouped together

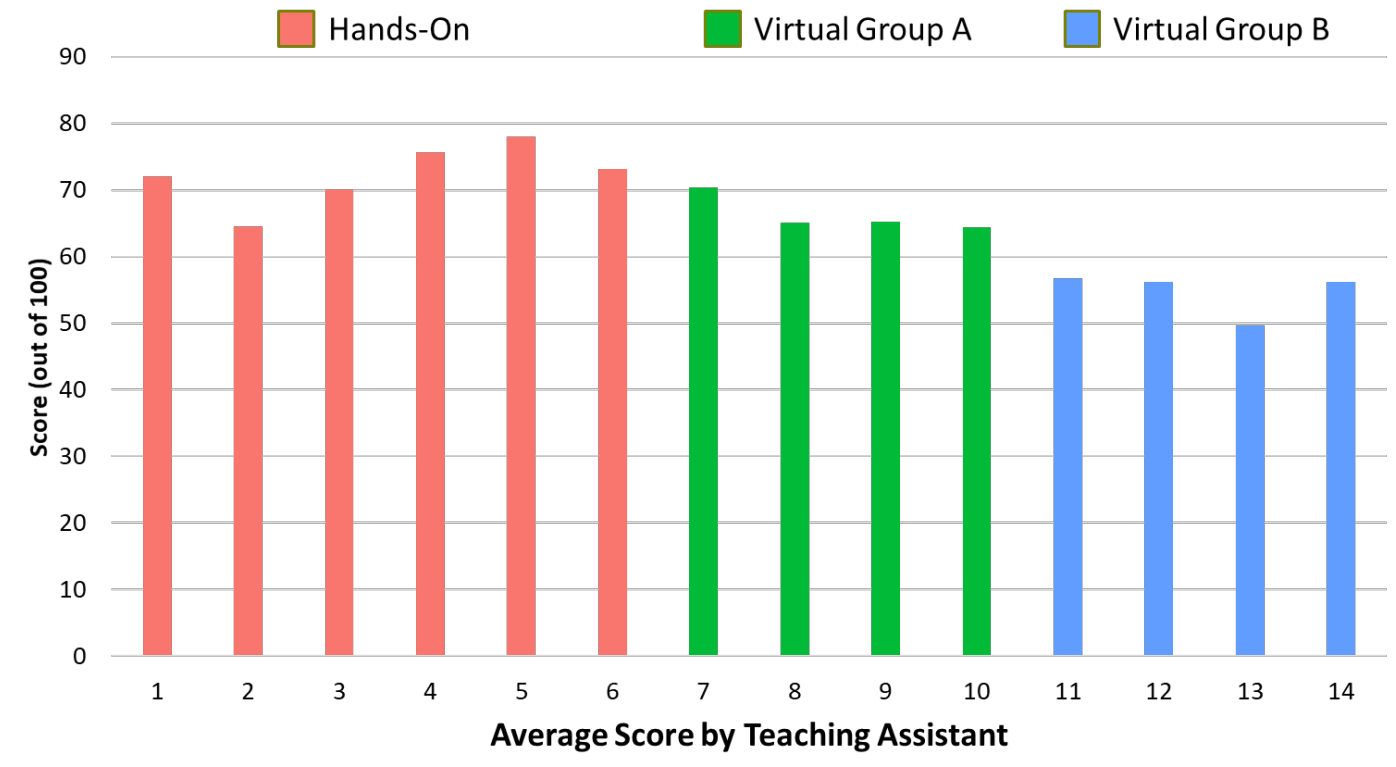

(Virtual Group A), and by TAs 11-14 were grouped together (Virtual Group B). The MANOVA was rerun with three groups instead of two to determine if an instructor-effect was leading to the differences between environments.

Figure 3: Average emotional satisfaction for each TAs sections. 


\section{Instructor Effect}

As each group had a sufficient sample size for use of Bonferroni corrections as the posthoc test, it was possible to compare the three groups to determine if the visual grouping was meaningful. Virtual Group A and Virtual Group B were compared and significant differences in the emotional satisfaction, usefulness of lab, and equipment usability scales were found (Table 5). These differences support the groupings of TAs, although it should be noted that there was no significant difference between the groups for the intellectual accessibility scale. These two groups were then compared separately with the Hands-On group to determine if splitting the virtual TAs changed the initial findings that virtual students had lower averages on the emotional satisfaction, intellectual accessibility, usefulness of lab, and equipment usability scales. When Virtual Group A was compared with the Hands-On group, no significant difference was found for any of the affective constructs (Table 5). However, there was a significant difference for all four scales when Virtual Group B was compared with the Hands-On group. These results suggest an instructor effect is present since the findings were not consistent when each virtual group was separately compared with the Hands-On group.

Table 5: p-values for posthoc comparisons between groups.

\begin{tabular}{|rcccc} 
& $\begin{array}{c}\text { Emotional } \\
\text { Satisfaction }\end{array}$ & $\begin{array}{c}\text { Intellectual } \\
\text { Accessibility }\end{array}$ & $\begin{array}{c}\text { Usefulness } \\
\text { of Lab }\end{array}$ & $\begin{array}{c}\text { Equipment } \\
\text { Usability }\end{array}$ \\
\hline Virtual Group A-Virtual Group B & $\mathbf{0 . 0 0 5}$ & 0.336 & $\mathbf{0 . 0 0 6}$ & $\mathbf{0 . 0 0 2}$ \\
Hands-On-Virtual Group A & 0.160 & 0.214 & 0.883 & 0.119 \\
Hands-On Virtual Group B & $<\mathbf{0 . 0 0 1}$ & $\mathbf{0 . 0 0 1}$ & $<\mathbf{0 . 0 0 1}$ & $<\mathbf{0 . 0 0 1}$
\end{tabular}

\section{DISCUSSION}

With an increase in the use of alternative laboratory environments, it is important to measure differences that exist between the alternative and traditional hands-on environments. However, there has been a lack of affective instruments that have been designed or modified for the laboratory environment to measure these differences. Therefore, an anxiety scale adapted from the CLAI and ASCI, the emotional satisfaction and intellectual accessibility scales from the ASCI, the initial interestfeeling and initial interest-value scales, and the usefulness of lab scale from the VPEQ were modified for the laboratory environment and the psychometric properties were tested. All scales had acceptable fit indices after modification and measurement invariance was established, as noted in Tables 1 and 2. 
The three-factor model of anxiety, emotional satisfaction, and intellectual accessibility and the twofactor model of initial interest-feeling and initial interest-value had acceptable fit and produced correlations that were similar to previously reported values. The scales for open-endedness of lab and equipment usability were not tested with factor models as they had too few items but were included when running the MANOVA. With all scales functioning as intended and measurement invariance established, the group means were compared to determine what affective differences may exist between environments.

The students who completed the virtual Beer's Law experiment had a higher average anxiety score and lower averages on all other affective aspects. These findings were in agreement with previous research ${ }^{23}$ that found students experience less favorable affective outcomes when completing a virtual chemistry experiment in the LearnSmart environment as compared with the traditional hands-on environment. However, when instructor effect was accounted for in the present study, the results were split. No significant differences were detected between the scale scores of students in the traditional hands-on environment and students who completed the experiment in the virtual environment with a TA in group A (Hands-On-Virtual Group A in Table 5). However, all four scales showed a significant difference when the same comparison was made between students in the traditional hands-on environment and students who had a TA in Virtual Group B (Hands-On-Virtual Group B in Table 5). This instructor effect indicates that which TA the students had may be a more decisive factor in their scores on the affect constructs measured than which environment they completed the experiment in. One possible explanation for the difference seen in students' affective scores could be due to the TAs prior teaching experience. One TA in the Hands-On group, one TA in Virtual Group A, and three TAs in virtual group B were all teaching laboratories for the first time at this institution. It was possible that the added burden of teaching in a new environment, while still becoming generally comfortable with teaching, could have negatively impacted their section. If the virtual experiment took place after these TAs had gained additional teaching experience, it is possible that the difference between TAs would have been smaller. 


\section{CONCLUSIONS}

Although previous research on virtual chemistry laboratories has indicated no statistical differences in cognitive and psychomotor outcomes, little research had been presented on affective differences. Therefore, this research adapted and modified existing affective scales for the chemistry laboratory and administered them to students conducting a virtual Beer's law experiment and a traditional hands-on version of the experiment. The scales were tested for the laboratory environment context to ensure they were functioning as intended in the new context. Evidence for the response process validity was provided by student interviews. All scales produced acceptable fit indices when tested with a single-factor, congeneric, CFA model, which supports structural validity. Internal consistency reliability of the scales was supported with acceptable McDonald's omega values. This evidence provides support that it is possible to modify existing affective measures that have been designed for, and tested in, the classroom setting and apply them to the laboratory setting. With functioning affective scales for the laboratory, future studies can increase the body of literature on affective laboratory outcomes.

The functional scales were used to determine what differences in affective constructs may exist between a virtual experiment and a hands-on experiment. After controlling for instructor-effect, statistical differences were split based on which TA the students had. It is possible that the TA's comfort level with teaching the experiment in the environment they were assigned to impacted the students' affective aspects in the laboratory. With previous studies finding no difference in the cognitive and psychomotor domain and this study finding split differences in the affective domain when controlling for instructor effect, laboratory coordinators have evidence that seeking an alternative environment may not significantly harm their student outcomes for this particular experiment. However, the possibility of an instructor-effect should be taken into consideration when considering how students react to an alternative environment.

Recently, there has been a call for future studies to better understand the impact laboratories have on student learning. ${ }^{78}$ Future work should be conducted to examine the effect that a TA has on the student's experience. With a lack of uniform TA training or experience, it is possible that students completing identical experiments with a different TA may have drastically different experiences and 
outcomes. The best practices for training TAs are not well understood 79 and future research should investigate how the instructor-effect can be mitigated through rigorous TA training programs. In this study, these differences were found to impact affective outcomes more than the environment the students completed the experiment in.

\section{CONSIDERATIONS FOR FUTURE RESEARCH}

Knowing that there is an instructor effect present in this study, and possibly other studies, on the chemistry laboratory, future research should aim to control for instructor effects as much as possible. Suggestions include increasing the length of training time around the virtual experiment and/or qualitatively observing each classroom to make note of possible differences between TAs. Although it is difficult to ensure different instructors are equal across sections, taking steps early in the research process to control for the possible differences will allow for clarity on if any findings are due to the intervention or the instructor.

\section{LIMITATIONS}

While split differences between environments were found in this specific context, the results should not be generalized to other contexts without further testing. The traditional hands-on experiment the students completed was a confirmatory lab in nature and the results may be different from an inquiry-based, project-based, or other types of hands-on curricula. The virtual experiment was completed using a modified procedure in the LearnSmart Labs and the results may be different if a different virtual environment is used. The research took place at Portland State University, a nontraditional urban university in the Pacific Northwest, and the results may be different at different institutions. Future work should focus on testing affective differences between environments in a wide range of contexts to determine how generalizable these findings are.

Additionally, although the students enrolled randomly in sections and did not know which environment or TA they would have at the time of registration, it is still possible that a larger portion of students with negative attitudes towards chemistry enrolled in the four virtual sections with less favorable affective aspects. 'Initial interest' was measured to attempt to capture this difference but may not have adequately captured all incoming differences. As such, it would not be appropriate to use the modified and newly created affective scales to make conclusions about individual TA effectiveness. 
There are many factors that could influence the differences seen and it is possible that those factors could be outside of the TAs control. Lastly, the analysis was conducted by combining sections to have enough power to detect differences between environments, which leaves the possibility that the findings are not representative of an individual's experience as there may be differences between environments for individual students that were not captured when the data was aggregated.

\section{ASSOCIATED CONTENT}

The Supporting Information is available on the ACS Publications website at DOI:

10.1021/acs.jchemed.XXXXXXX. Administered survey items, initial MANOVA results, and scale scores by TA group.

\section{AUTHOR INFORMATION}

*E-mail: jbarbera@pdx.edu

\section{ACKNOWLEDGMENTS}

We would like to thank the graduate teaching assistants, students, the laboratory coordinator, and stockroom staff that were involved with this work. Without all of them, this study would not have been possible. Additionally, we would like to thank McGraw-Hill Education who generously allowed us to use the LearnSmart Labs platform for this work.

\section{REFERENCES}

1. Seaman, J. E.; Allen, I. E.; Seaman, J., Grade Increase: Tracking Distance Education in the United States. Babson Survey Research Group 2018, http://www.onlinelearningsurvey.com/highered.html (accessed July 2019).

2. Committee on Professional Training Undergraduate Professional Education in Chemistry: ACS Guidelines and Evaluation Procedures for Bachelor's Degree Programs; American Chemical Society Washington, DC: 2015.

3. Kennepohl, D., Using home-laboratory kits to teach general chemistry. Chem. Educ. Res. Pract. 2007, 8 (3), 337-346.

4. Hoole, D.; Sithambaresan, M., Analytical chemistry labs with kits and CD-based instructions as teaching aids for distance learning. J. Chem. Educ. 2003, 80 (11), 1308-1310.

5. Boschmann, E., Teaching chemistry via distance education. J. Chem. Educ. 2003, 80 (6), 704-708.

6. Ma, J.; Nickerson, J. V., Hands-on, simulated, and remote laboratories: A comparative literature review. ACM Computing Surveys (CSUR) 2006, 38 (3), 1-24.

7. Herranz, J.; Carro, G.; Contreras, A.; Camacho, E. M.; Garcia-Loro, F.; Gil, M. C. In From a Hands-on Chemistry Lab to a Remote Chemistry Lab: Challenges and Constrains, Online Engineering \& Internet of Things, Columbia University, Auer, M.; Zutin, D., Eds. Springer:New York, pp 125-131.

8. Perkins, K.; Adams, W.; Dubson, M.; Finkelstein, N.; Reid, S.; Wieman, C.; LeMaster, R., PhET: 
9. Clark, T. M.; Chamberlain, J. M., Use of a PhET interactive simulation in general chemistry laboratory: Models of the hydrogen atom. J. Chem. Educ. 2014, 91 (8), 1198-1202.

10. Winkelmann, K.; Keeney-Kennicutt, W.; Fowler, D.; Macik, M., Development, Implementation, and Assessment of General Chemistry Lab Experiments Performed in the Virtual World of Second Life. J. Chem. Educ. 2017, 94 (7), 849-858.

11. Winkelmann, K.; Scott, M.; Wong, D., A study of high school students' performance of a chemistry experiment within the virtual world of second life. J. Chem. Educ. 2014, 91 (9), 1432-1438.

12. Reece, A. J.; Butler, M. B., Virtually the Same: A Comparison of STEM Students Content Knowledge, Course Performance, and Motivation to Learn in Virtual and Face-to-Face Introductory Biology Laboratories. Journal of College Science Teaching 2017, 46 (3), 83-89.

13. Woodfield, B. F.; Andrus, M. B.; Andersen, T.; Miller, J.; Simmons, B.; Stanger, R.; Waddoups, G. L.; Moore, M. S.; Swan, R.; Allen, R., The virtual ChemLab project: A realistic and sophisticated simulation of organic synthesis and organic qualitative analysis. J. Chem. Educ. 2005, 82 (11), 1728-1735.

14. Woodfield, B. F.; Catlin, H. R.; Waddoups, G. L.; Moore, M. S.; Swan, R.; Allen, R.; Bodily, G., The virtual ChemLab project: a realistic and sophisticated simulation of inorganic qualitative analysis. J. Chem. Educ. 2004, 81 (11), 1672-1678.

15. Hawkins, I.; Phelps, A. J., Virtual laboratory vs. traditional laboratory: Which is more effective for teaching electrochemistry? Chem. Educ. Res. Pract. 2013, 14 (4), 516-523.

16. Bloom, B. S.; Engelhart, M. D.; Furst, E. J.; Hill, W. H.; Krathwohl, D. R., Taxonomy of educational objectives, handbook I: The cognitive domain. David McKay: New York, 1956.

17. Simpson, E., Educational Objectives in the Psychomotor Domain. In Behavioral Objectives in Curriculum Development: Selected Readings and Bibliography, Educational Technology Publications: New Jersey, 1971.

18. Krathwohl, D. R.; Bloom, B. S.; Masia, B. B., Taxonomy of educational objectives, handbook ii: Affective domain. New York: David McKay Company. Inc. ISBN 0-679-30210-7, 0-582-32385 1964, 1.

765 19. Hunt, W. C. Teaching and Learning in the Affective Domain: A Review of the Literature; Washington Office of the State Superintendent of Public Instruction: Olympia, WA, 1987.

20. Hofstein, A., The role of laboratory in science teaching and learning. In Sci. Educ., Springer: 2017; pp 357-368.

21. Pyatt, K.; Sims, R., Virtual and physical experimentation in inquiry-based science labs: Attitudes, performance and access. J. Sci. Educ. Technol. 2012, 21 (1), 133-147.

22. Grant, D. A., The latin square principle in the design and analysis of psychological experiments. Psychol. Bull. 1948, 45 (5), 427-442.

23. Enneking, K. M.; Breitenstein, G. R.; Coleman, A. F.; Reeves, J. H.; Wang, Y.; Grove, N. P., The Evaluation of a Hybrid, General Chemistry Laboratory Curriculum: Impact on Students' Cognitive, Affective, and Psychomotor Learning. J. Chem. Educ. 2019, 96 (6), 1058-1067.

24. Johnstone, A. H., Macro- and micro-chemistry. School Science Review 1982, (64), 377-379.

25. Irby, S. M.; Borda, E. J.; Haupt, J., Effects of Implementing a Hybrid Wet Lab and Online Module Lab Curriculum into a General Chemistry Course: Impacts on Student Performance and Engagement with the Chemistry Triplet. J. Chem. Educ. 2017, 95 (2), 224-232.

$780 \quad 26 . \quad$ Mack, M. R.; Hensen, C.; Barbera, J., Metrics and Methods Used To Compare Student Performance Data in Chemistry Education Research Articles. J. Chem. Educ. 2019, 96 (3), 401-413.

27. Chatterjee, S.; Williamson, V. M.; McCann, K.; Peck, M. L., Surveying students' attitudes and perceptions toward guided-inquiry and open-inquiry laboratories. J. Chem. Educ. 2009, 86 (12), 1427-1432.

28. Lang, A. S.; Bradley, J.-C., Chemistry in second life. Chem. Cent. J. 2009, 3 (1), 14.

785 29. Murray-Rust, P., Chemistry for everyone. Nature 2008, 451 (7179), 648-651.

30. Casanova, R. S.; Civelli, J. L.; Kimbrough, D. R.; Heath, B. P.; Reeves, J. H., Distance learning: A viable alternative to the conventional lecture-lab format in general chemistry. J. Chem. Educ. 2006, 83 (3), 501-507.

31. Sonnenwald, D. H.; Whitton, M. C.; Maglaughlin, K. L., Evaluating a scientific collaboratory: Results of a controlled experiment. ACM Trans Comput Hum Interact 2003, 10 (2), 150-176.

$790 \quad 32 . \quad$ Scanlon, E.; Colwell, C.; Cooper, M.; Di Paolo, T., Remote experiments, re-versioning and re-thinking science learning. Comput. Educ. 2004, 43 (1-2), 153-163.

33. Corter, J. E.; Esche, S. K.; Chassapis, C.; Ma, J.; Nickerson, J. V., Process and learning outcomes from remotely-operated, simulated, and hands-on student laboratories. Comput. Educ. 2011, 57 (3), 2054-2067. 
34. Kennepohl, D.; Baran, J.; Currie, R., Remote instrumentation for the teaching laboratory. J. Chem. Educ. 2004, 81 (12), 1814-1816.

35. National Research Council, Discipline-based education research: Understanding and improving learning in undergraduate science and engineering. 2012, National Academies Press: Washington, DC, https://doi.org/10.17226/13362 (accessed July 2019).

36. Galloway, K. R.; Bretz, S. L., Development of an assessment tool to measure students' meaningful learning in the undergraduate chemistry laboratory. J. Chem. Educ. 2015, 92 (7), 1149-1158.

37. Galloway, K. R.; Bretz, S. L., Measuring meaningful learning in the undergraduate general chemistry and organic chemistry laboratories: a longitudinal study. J. Chem. Educ. 2015, 92 (12), 2019-2030.

38. Schmidt-McCormack, J. A.; Muniz, M. N.; Keuter, E. C.; Shaw, S. K.; Cole, R. S., Design and implementation of instructional videos for upper-division undergraduate laboratory courses. Chem. Educ. Res. Pract. 2017, 18 (4), 749-762.

39. Flaherty, A.; O'Dwyer, A.; Mannix-McNamara, P.; Leahy, J., Evaluating the Impact of the "Teaching as a Chemistry Laboratory Graduate Teaching Assistant" Program on Cognitive and Psychomotor Verbal Interactions in the Laboratory. J. Chem. Educ. 2017, 94 (12), 1831-1843.

40. Galloway, K. R.; Bretz, S. L., Using cluster analysis to characterize meaningful learning in a first-year university chemistry laboratory course. Chem. Educ. Res. Pract. 2015, 16 (4), 879-892.

41. Bowen, C. W., Development and score validation of a chemistry laboratory anxiety instrument (CLAl) for college chemistry students. Educ. Psychol. Meas. 1999, 59 (1), 171-185.

42. Cooper, M. M.; Sandi-Urena, S., Design and validation of an instrument to assess metacognitive skillfulness in chemistry problem solving. J. Chem. Educ. 2009, 86 (2), 240-245. 43. Grove, N.; Bretz, S. L., CHEMX: An instrument to assess students' cognitive expectations for learning chemistry. J. Chem. Educ. 2007, 84 (9), 1524-1529.

44. Bauer, C. F., Beyond "student attitudes": Chemistry self-concept inventory for assessment of the affective component of student learning. J. Chem. Educ. 2005, 82 (12), 1864-1870.

45. Bauer, C. F., Attitude toward chemistry: a semantic differential instrument for assessing curriculum impacts. J. Chem. Educ. 2008, 85 (10), 1440-1445.

46. Xu, X.; Lewis, J. E., Refinement of a chemistry attitude measure for college students. J. Chem. Educ. 2011, 88 (5), 561-568.

47. Adams, W. K.; Wieman, C. E.; Perkins, K. K.; Barbera, J., Modifying and validating the Colorado Learning Attitudes about Science Survey for use in chemistry. J. Chem. Educ. 2008, 85 (10), 1435-1439. 48. Liu, Y.; Ferrell, B.; Barbera, J.; Lewis, J. E., Development and evaluation of a chemistry-specific version of the academic motivation scale (AMS-Chemistry). Chem. Educ. Res. Pract. 2017, 18 (1), 191-213.

49. $\quad$ Furr, R. M., Psychometrics: an introduction. Sage Publications: Thousand Oaks, CA, 2017.

50. Arjoon, J. A.; Xu, X.; Lewis, J. E., Understanding the state of the art for measurement in chemistry education research: Examining the psychometric evidence. J. Chem. Educ. 2013, 90 (5), 536-545.

830 51. Barbera, J.; VandenPlas, J., All assessment materials are not created equal: the myths about instrument development, validity, and reliability. In Investigating classroom myths through research on teaching and learning, 2011; Vol. 1074, pp 177-193.

52. Schwartz, P.; Barbera, J., Evaluating the content and response process validity of data from the chemical concepts inventory. J. Chem. Educ. 2014, 91 (5), 630-640.

835 53. Milfont, T. L.; Fischer, R., Testing measurement invariance across groups: Applications in cross-cultural research. Int. J. Psychol. Res. 2010, 3 (1), 111-130.

54. Mack, M. R.; Hensen, C.; Barbera, J., Metrics and Methods Used To Compare Student Performance Data in Chemistry Education Research Articles. J. Chem. Educ. 96 (3), 401-413.

55. Anderson, L. W.; Bourke, S. F., Assessing affective characteristics in the schools. Routledge: 1981.

840 56. Ferrell, B.; Barbera, J., Analysis of students' self-efficacy, interest, and effort beliefs in general chemistry. Chem. Educ. Res. Pract. 2015, 16 (2), 318-337.

57. Chan, J. Y.; Bauer, C. F., Effect of peer-led team learning (PLTL) on student achievement, attitude, and self-concept in college general chemistry in randomized and quasi experimental designs. JRST 2015, 52 (3), 319346.

845 58. Mooring, S. R.; Mitchell, C. E.; Burrows, N. L., Evaluation of a Flipped, Large-Enrollment Organic Chemistry Course on Student Attitude and Achievement. J. Chem. Educ. 2016, 93 (12), 1972-1983. 
59. Vishnumolakala, V. R.; Southam, D. C.; Treagust, D. F.; Mocerino, M.; Qureshi, S., Students' attitudes, self-efficacy and experiences in a modified process-oriented guided inquiry learning undergraduate chemistry classroom. Chem. Educ. Res. Pract. 2017, 18 (2), 340-352.

60. Heise, D. R., The semantic differential and attitude research. Attitude measurement 1970, 4, $235-253$.

61. Ferrell, B.; Phillips, M. M.; Barbera, J., Connecting achievement motivation to performance in general chemistry. Chem. Educ. Res. Pract. 2016, 17 (4), 1054-1066.

62. Harackiewicz, J. M.; Durik, A. M.; Barron, K. E.; Linnenbrink-Garcia, L.; Tauer, J. M., The role of achievement goals in the development of interest: Reciprocal relations between achievement goals, interest, and performance. J. Educ. Psychol. 2008, 100 (1), 105-122.

63. American Educational Research Association; American Psychological Association; National Council on Measurement in Education; Joint Committee on Standards for Educational Psychological Testing, Standards for educational and psychological testing. Amer Educational Research Assn: 1999.

64. Rosseel, Y., Lavaan: An R package for structural equation modeling and more. Version 0.5-12 (BETA). J. Stat. Softw. 2012, 48 (2), 1-36.

65. Kurbanoglu, N. I.; Akim, A., The relationships between university students' chemistry laboratory anxiety, attitudes, and self-efficacy beliefs. Aust. J. Teach. Educ. 2010, 35 (8), 48-59.

66. Hu, L. t.; Bentler, P. M., Cutoff criteria for fit indexes in covariance structure analysis: Conventional criteria versus new alternatives. Strct. Equ. Modeling 1999, 6 (1), 1-55.

865 67. Komperda, R.; Pentecost, T. C.; Barbera, J., Moving beyond Alpha: A Primer on Alternative Sources of Single-Administration Reliability Evidence for Quantitative Chemistry Education Research. J. Chem. Educ. 2018, 95 (9), 1477-1491.

68. Cheung, G. W.; Rensvold, R. B., Evaluating goodness-of-fit indexes for testing measurement invariance. structural equation modeling a multidisciplinary journal 2002, 9 (2), 233-255.

870 69. Duncan, O. D., Introduction to structural equation models. Academic Press, Inc: New York, New York, 1975.

70. Kenny, D. A.; Kaniskan, B.; McCoach, D. B., The performance of RMSEA in models with small degrees of freedom. Sociol. Methods. Res. 2015, 44 (3), 486-507.

71. Cohen, J., A power primer. Psychol. Bull. 1992, 112 (1), 155-159.

72. Xu, X.; Villafane, S. M.; Lewis, J. E., College students' attitudes toward chemistry, conceptual knowledge and achievement: structural equation model analysis. Chem. Educ. Res. Pract. 2013, 14 (2), 188-200.

73. Boone, H. N.; Boone, D. A., Analyzing likert data. Journal of extension 2012, 50 (2), 1-5.

74. De Maesschalck, R.; Jouan-Rimbaud, D.; Massart, D. L., The mahalanobis distance. Chemometr. Intell. Lab. Syst. 2000, 50 (1), 1-18.

75. Potthast, M. J., Confirmatory factor analysis of ordered categorical variables with large models. Br. J. Math. Stat. Psychol. 1993, 46 (2), 273-286.

76. Olson, C. L., Comparative robustness of six tests in multivariate analysis of variance. J. Am. Stat. Assoc. 1974, 69 (348), 894-908.

77. Richardson, J. T., Eta squared and partial eta squared as measures of effect size in educational research. Educ. Res. Rev. 2011, 6 (2), 135-147.

78. Bretz, S. L., Evidence for the Importance of Laboratory Courses. J. Chem. Educ. 2019, 96 (2), 193-195.

79. Reeves, T. D.; Marbach-Ad, G.; Miller, K. R.; Ridgway, J.; Gardner, G. E.; Schussler, E. E.; Wischusen, E. W., A conceptual framework for graduate teaching assistant professional development evaluation and research. CBE Life Sci. Educ. 2016, 15 (2), 1-9. 